AN EVALUATION OF THE FIRST YEAR OF FAMILY HEALTH NURSING

PRACTICE IN SCOTLAND

\author{
Authors: $\quad$ Colin Macduff*, RMN, RGN, BA (Hons), MSc \\ Research Fellow \\ Dr Bernice JM West, RGN, MA (Hons), PhD \\ Director \\ Address: (for both authors) \\ Centre for Nurse Practice Research and Development, \\ The Robert Gordon University, Garthdee Road, Aberdeen AB10 7QG \\ Contact: $\quad *$ corresponding author \\ Tel: 01224262647 \\ Fax: 01224262630 \\ E mail: c.macduff@rgu.ac.uk
}




\title{
AN EVALUATION OF THE FIRST YEAR OF FAMILY HEALTH NURSING
} PRACTICE IN SCOTLAND

\begin{abstract}
Scotland has led enactment of the new World Health Organisation (Europe) Family Health Nurse concept. This paper presents research which evaluated the initial operation and impact of the role in remote and rural regions of Scotland. Through use of a multiplex research design informed by ideas from realistic evaluation, fourth generation evaluation and case study research, an initial typology of practice was constructed. The new FHN role typically supplemented, rather than supplanted, pre-existing community nursing services. Implications arising from key findings are discussed in relation to Scottish, UK and European nursing and primary care perspectives.
\end{abstract}

Keywords: Family Health Nurse, community nursing practice, primary care, evaluation research 


\section{Introduction}

In 1998 the World Health Organisation (WHO) Europe introduced The Family Health Nurse (FHN) concept as a possible means of developing and strengthening family and community oriented health services (WHO Europe 1998a). Within the HEALTH 21 health policy framework it was proposed that this new type of nurse would make "a key contribution within a multi-disciplinary team of health care professionals to the attainment of the 21 health targets set in the policy." In this context the FHN and the Family Health Physician were posited as the key professionals at the hub of a network of primary care services.

The proposed role of the FHN was multifaceted and included helping individuals, families and communities to cope with illness and to improve their health. At WHO Europe level it was initially envisaged that 18 European countries would take part in the development of this new role through parallel processes of education and implementation. These linked national initiatives were to be termed "pilot" projects and would include evaluation of structures, processes and outcomes. To date, however, Scotland has been far ahead of other counties in terms of enactment and is the only country to have completed a pilot project. This paper reports and discusses the main findings from the evaluation of the first year of FHN practice in Scotland.

\section{Community nursing in the UK}

Before describing this project it is important to note that Scottish nursing operates within the UK framework, whereby nurses working in community settings must be registered with the National Nursing and Midwifery Council (NMC; formerly known as the UKCC) who regulate standards of practice. In addition many nurses also hold a community specialist practitioner qualification such as District Nurse, Health Visitor or General Practice Nurse. Other specialist nurses working in communities may have expertise in the care of people with specific disease (e.g. Macmillan Nurses for cancer care; Diabetic Specialist Nurses). Midwives are also active in UK communities, caring for women through pregnancy and childbirth.

This diverse array of professionals has evolved in an attempt to meet the health care demands of varied populations. However the community nursing workforce in the UK is frequently criticised as being over-specialised and fragmented (Hyde 1995) to an extent that may be dysfunctional not only for the professions, but also for the public whom they serve. 
These types of concerns appear to have informed recent policy documents within Scotland. Nursing for Health (Scottish Executive Health Department 2001) states that "The Scottish Executive will review with all interested parties the outcomes of the new public health and family health nurse programmes with a view to having only two routes to community specialist practice - the Family Health Nurse and the Public Health Nurse".

\section{The Scottish project}

Much more specifically, however, the Scottish Executive Health Department (SEHD) saw the FHN concept as a potential solution to some of the problems of providing health care in Scotland's remote and rural regions. These regions are geographically isolated and tend to have declining populations with relatively poor health profiles. There is difficulty in recruiting, developing and retaining all health professionals. Within nursing and midwifery it has become increasingly difficult to sustain the traditional double duty roles (e.g. where one person is a qualified District Nurse and Midwife) and triple duty roles (e.g. where one person is a qualified District Nurse, Health Visitor and Midwife).

Against this background the SEHD felt that the multifaceted nature of the FHN concept could potentially be useful. This broad scope is manifest in the initial FHN role definition which states that: "The Family Health Nurse will: help individuals and families to cope with illness and chronic disability, or during times of stress, by spending a large part of their time working in patients' homes and with their families. Such nurses give advice on lifestyle and behavioural risk factors, as well as assisting families with matters concerning health. Through prompt detection they can ensure that the health problems of families are treated at an early stage. With their knowledge of public health and social issues and other social agencies, they can identify the effects of socio-economic factors on a family's health and refer them to the appropriate agency. They can facilitate the early discharge of people from hospital by providing nursing care at home, and they can act as the lynchpin between the family and the family health physician, substituting for the physician when the identified needs are more relevant to nursing expertise” (WHO Europe 1998a).

For the purposes of the Scottish pilot project the SEHD summarised the principles of the FHN role as:

- A skilled generalist role encompassing a broad range of duties, dealing as the first point of contact with any issues that present themselves and referring on to specialists where a greater degree of expertise is required 
- A model based on health rather than illness - the FHN would be expected to take a lead role in preventing illness and promoting health as well as caring for those members of the community who are ill and require nursing care

- A role founded on the principle of caring for families rather than just the individuals within them.

- A concept of the nurse as first point of contact

Early in 2001 a 2 year pilot project began. Three regions in northern Scotland were involved initially, with a fourth joining the project in 2002. A Scottish University was commissioned to provide the educational programme to prepare nurses from these regions. This took the form of a 40 week degree-level course that was completed by a total of 31 students (11 in the first cohort in 2001; 20 in the second cohort in 2002). These students were typically very experienced local nurses. Twenty were midwives and twenty had no specific community specialist nurse qualification. Nine were already qualified District Nurses and three of the second cohort were qualified health visitors. The first cohort returned to their home sites to work as qualified FHNs at the start of 2002.

The authors were commissioned to undertake independent research to evaluate the operation and impact of family health nursing. This included evaluation of the educational course, which is reported in the full evaluation document (Macduff and West 2003). The objectives of the evaluation that pertained to evaluation of the first year of FHN practice (2002) were:

- To compare the coverage and extent of service provided by current primary health care nursing services and the subsequent coverage of service provided by the FHN.

- To explore the operation of the FHN model, focusing on the nature of the services provided and drawing comparisons between the pilot sites.

- To identify relevant stakeholders' perceptions of the FHN model.

- To draw out implications from the study's findings for the future provision of education for FHNs and for the extension of service provision to other areas of Scotland, including urban areas. 


\section{Methods}

Concurrent evaluation of an evolving, multi-factorial, and geographically diverse development such as the FHN initiative mitigates against the use of quasi-experimental research designs that depend on notions of control. Accordingly our research was grounded more in the traditions of qualitative enquiry, while also incorporating survey methods.

$$
\checkmark
$$

In evaluating practice our overall aim was to identify emergent patterns of context, process and outcome that might characterise each of the local sites involved in the pilot (i.e. context of development; process of engagement and outcome of practice). This approach adapts Pawson and Tilley (1997)'s realistic evaluation framework so that process rather than mechanism is studied. The goals were to clarify what FHN practice was in these settings, and then clarify how, and to what extent, the FHN role worked under various circumstances. As such, the ten FHN sites active during 2002 were seen as the main units of analysis in this study. Explanatory case study methodology (Yin 1994) also informed this approach and knowledge was built at two distinct levels in order to explore the operation of the FHN model and draw comparisons between the pilot sites.

\subsection{Data collection}

Firstly, at the micro level, a set of case studies was conducted which focused on the care received by six families in different locations where FHNs were employed. This involved indepth, semi-structured interviews with family members, the FHN and a maximum of two other key health care professionals involved in delivering care. These cases were selected from a pool of 20 "tracer families" ( 2 for each FHN site) whose progress was followed during the latter part of 2002. Details of the selection of tracer families and case study families are given in Figure 1.

Study of the operation of the FHN model was further contextualised through the researchers making several visits to each site during the course of the project. This aspect of the study design was influenced by ideas from fourth generation evaluation (Guba and Lincoln 1989), particularly in regard to stakeholder consultation. Profiles of these sites were constructed from the following data sets:

- Available documentation on the epidemiology and demography of each site location, including any extant health needs assessments 
- The FHN students' community portrait documents

- Summary profiles of all health care staff comprising the core Primary Health Care Team (PHCT) for each site. Summary profiles of all other relevant health, community and social care staff involved closely with the PHCT at each site (e.g. social workers; voluntary sector workers; teachers). Together these groups comprised the "professional stakeholders"

- Community nursing caseload and mix data available from routine collations (very variable in quality) and specifically obtained in-person by the research team

- Field notes from interviews with key site personnel. These gathered details of cultural context; working practices; referrals; and local resources

- Field notes from telephone discussions with practising FHNs (made throughout project)

- Field notes from direct observations of FHNs' work with selected families

- Scrutiny of the nursing case notes of the 20 "tracer families"

Late in 2001 we mailed a questionnaire to professional stakeholders at each site seeking their baseline perceptions of the imminent FHN role. The questionnaire included a number of questions that used the semantic differential technique (Osgood 1957) to gauge anticipated magnitude of practice change and impact. This was repeated a year later using a very similar questionnaire to gauge perceptions of the actual development in practice. A similar, but more restricted repeated consultation exercise was conducted with twenty randomly selected members of the public ("lay stakeholders") at seven of the FHN sites. One regional research ethics committee refused permission for lay stakeholder consultation at the three FHN sites within their jurisdiction. 


\subsection{Data analysis}

Data from these questionnaires were entered on to SPSS V10 databases and data entry checking was undertaken. Frequencies were generated in order to summarise and describe quantitative data. Textual comments were collated and analysed in terms of content frequency and thematic coverage. Secondary analysis examined the reliability of the questionnaires in terms of internal consistency using the alpha co-efficient.

Qualitative content analysis (Bryman 2001; Priest et al 2002) was applied to all the family case study interviews so that the emergent themes within each family case could be mapped in terms of which were common to all interviewees and which were distinct. Figure 2 gives an overview of how this process informed the overall process of analysis and synthesis of FHN practice data.

As Figure 2 shows, it was possible towards the end of 2002 to draw on all the data sets in order to analyse emergent patterns of practice at each FHN site in terms of context of development, process of engagement and outcome. This in turn allowed knowledge to be built at the macro level whereby the ten, site-specific case studies could be compared and contrasted. In this way a typology of family health nursing practice was constructed. Moreover it was possible to gain an overview of family health nursing practice by drawing together the common themes that emerged across the ten sites. 


\section{Findings}

\subsection{Context of practice}

During 2002 there were ten sites where an FHN sustained activity over the whole year. All ten FHN sites fit the Scottish Household Survey (SEHD 2000) definition of remote and rural, in that their main settlements all have a population of_less than 3000 and are more than a 30 minute drive time from a settlement of 10,000 people or more.

The ten FHNs all returned to work at home bases where they had previously worked primarily as community staff nurses or District Nurses. The predominant contextual influence on the operation of the new FHN role tended to be the locus of established district nursing services. Thus, during the first year of practice, the FHN site was defined as a distinct geographic area whose population were served by one (or occasionally two) district nursing team(s), within which an FHN was working. Other health professionals whose work involved the provision of primary care services to the population of this site were known as the PHCT. At nine of the ten sites the new FHNs inherited either a part of a large district nursing caseload, or the whole of a small one. From this basis the new role was then developed.

Close scrutiny of pre-existing district nursing caseloads revealed very wide variation across sites in regard to what constituted a caseload (e.g. what people were visited for; frequency of visiting; entry and exit from caseload lists). This made meaningful comparison very difficult. Routinely collected data on nursing activity was virtually worthless in this regard as recording practices varied so widely. This problem has long been recognised within UK community nursing (Goodman et al 2003). At the end of the day, perceived burden of caseload (i.e. "nonheavy" or "heavy") proved as useful a proxy indicator as any, especially since this was crosschecked with other members of the PHCT. Thus we used this indicator in constructing the typology of practice.

\subsection{Typology of practice}

As Figure 2 shows, the typology of practice was built through analysis and synthesis of a range of data. Table 1 presents the resultant typology. This summarises details of the four distinct practice types which emerged, in terms of their constituent context-process-outcome patterns. Further explanation of each type is now given. 
The High scope-slow build pattern of practice was found in two small island sites with very small PHCTs. The FHNs "inherited" district nursing caseloads that were small and had relatively few patients needing regular, intensive nursing input. Workload fluctuated but on the whole there was high scope for autonomous practice development. On the other hand there was the responsibility to provide nursing services for the whole island population and this brought with it the particular demands of being almost constantly on-call and being expected to deal with a very wide range of clinical eventualities. Thus context tended to be the predominant aspect in this pattern. Stakeholders perceived little change:

"FHN could have been modelled on what was happening here before i.e. District Nurse always providing a high level of care due to the exceptional circumstances of a small isolated community" (lay stakeholder)

The predominant characteristic of the Slow build-key ally pattern was the presence within the core PHCT of at least one fellow professional who recognised the need for the role and actively supported it through routine working practice (e.g. by referring families to the FHN). The three sites that shared this pattern covered large, sparsely populated geographic areas and it was notable that the key allies were always based in the same specific geographic patch as the FHN, rather than at a different base within the whole PHCT site. At one site the FHN already had a small pre-existing midwifery caseload and expanded her health work with these families through very active support from a Health Visitor colleague. Typically this pattern featured small scale expansions into areas where there was an opportunity for service development and/or an acknowledged local gap in services.

The Slow/No go pattern was seen in a variety of geographic contexts, but the predominant characteristic was the super-imposition of the role on to a heavy district nursing caseload, combined with an underlying lack of active support for the new role within the core PHCT. Other team members generally did not engage with the role to the extent that it could be seen as at all integrated with team practice. Rather there was pre-occupation with the maintenance of existing services and service priorities. Often this reflected persistent professional perceptions that there was no clear need for this sort of new role.

\footnotetext{
"Existing team networks well and has staff who are motivated and continuously professionally develop. We should concentrate on development of existing team" (professional stakeholder)
} 
Consequently these FHNs struggled to introduce the role, and development of family work was sporadic and difficult to sustain.

The distinctive Bold build pattern was unique to one site. Unlike all the other sites, the FHN role was not super-imposed on the pre-existing district nursing caseload. Rather the FHN built up a group of clientele "from scratch", primarily through active referrals from other health and social care professionals, but also through direct self-referrals from local people. As the year progressed the FHN developed work with a core group of around 20-25 families at any one time.

Such work often involved regular and sustained input, with intervention visits typically lasting between 60 to 90 minutes. Some colleagues saw this as a positive response to a real gap in service provision, but there was also some concern about who should receive this new service and whether a "two-tier" situation might be arising. These concerns were related to perceptions that the FHN caseload was separate and finite, and that the role was not integrated in the sense of being a necessary part of an open, on-call primary care service that would have to respond to the full range of community nursing and/or medical priorities. In this regard some colleagues questioned whether an FHN could truly be the first point of contact for local families.

As the year progressed the FHN vigorously developed more broad-based community work that focused on health promotion and empowerment. This came to assume around $30 \%$ of the FHN workload. This work was particularly well received by professional stakeholders within the wider health and social care community at this site.

"In area my local FHN works there are many medical/social interlinked problems which don't fit neatly into any "box". She has been aware of "bigger picture" and improved care/support"

Within the core PHCT however, some concerns remained that these FHN services were being developed in isolation from overall PHCT services.

"I am not sure if it's about creating a further role to DN and HV or about ensuring that the FHN role is accepted as being the way DNs should work, and their role changed accordingly" 
Anxieties over infringement of role boundaries remained a persistent feature during the first year of FHN practice at this site.

\subsection{Overview of family health nursing practice}

Although the emergent typology shows four distinct patterns of FHN practice, the majority share a significant common feature: the pervasive influence of the traditional work and concerns of the District Nurse role. During the first year of practice the majority of families who had involvement with an FHN did so because a family member was on the district nursing caseload. Where the FHN role failed to thrive that involvement remained focused predominantly on the individual and was virtually indistinguishable from "normal" district nursing. However it is important to note that all the FHNs felt that they were seeing these families much more as a whole and that this gave their practice a different quality. The difficulty was that this was not tangible for many of their close professional colleagues. To some extent this relates to the more general problem of the invisibility of nursing work conducted in peoples' homes (Griffiths and Luker 1994).

Across the ten sites there was an embedded "bottom line" that the introduction of the new role should not adversely affect the pre-existing level of district nursing service and should be sustained within pre-existing budgetary resources for nursing staff. This meant that where the role was developed it almost always supplemented rather than supplanted existing service.

The family health nursing documentation used by the FHNs in practice during most of 2002 was developed during the educational course in 2001. The documentation incorporated indepth assessment sections based on the Calgary Family Assessment Model (Wright and Leahey 1994). This featured the use of a genogram (diagram of the family constellation which depicts the relationships among family members for several generations and includes the mapping of health status/issues); an ecomap (diagram of a family's contact with others that gives an overview of social interactions and involvements); and in-depth questions on family power structure, dynamics, strengths and weaknesses. Such assessment was found to be a time consuming process that typically involved a number of lengthy home visits. During 2002 the FHNs all made extensive individual adaptations to the documentation in the light of practice. This resulted in a range of hybrid case notes that generally incorporated elements of pre-existing standard community nursing notes

Preventative work usually involved FHN input at secondary and tertiary levels for couples of the same generation, two generational families, and single people living alone (i.e. the typical 
client groups for district nursing). However most FHNs had ongoing input with at least one family with young children and some of these families had more complex structures. The input here was usually primary prevention relating to common aspects of family living (e.g. diet; exercise). Operationalising the family-as-client philosophy became more difficult where several households were involved, but this does not mean it was easy within single households. The logistical difficulties of seeing members of a family group individually and in combination cannot be overstated.

As the typology indicates, however, family health nursing was generally very well received by the families who had contact with the service. Some FHNs reported encountering families/family members who didn't wish to participate in the sort of in-depth assessment being offered, and this was usually because they found it intrusive and/or didn't see why it was needed. These sort of overt refusals were relatively rare and this is almost certainly attributable to the fact that the FHNs were very experienced community nurses who used their inter-personal skills to tailor the assessment content to the situations encountered.

\subsection{Lay stakeholders' views}

By aggregating responses from lay stakeholders across the ten sites it was possible to obtain overview. The useable response rate to the pre-implementation questionnaire was $42 \%$ (59/140) and an alpha coefficient of 0.83 suggested a satisfactory level of internal consistency. The useable response rate reduced to $35 \%$ post-implementation $(45 / 130)$ and the alpha coefficient of 0.76 was again reasonable.

Table 2 shows data from the 34 individuals who responded on consecutive occasions. This shows little change in these respondents' views. They remained unsure about several aspects of the FHN development but they also maintained a generally supportive attitude towards it. Respondents' written comments were often very insightful:

"If prevention is the aim, how is this to be delivered? Are families to be chosen on perceived socio-economic criteria or some other at-risk category, and once selection is made, how will subject be broached? I would rather see those in need of care get it as priority over some service that could be delivered in an intrusive and ad-hoc manner". 
A similar aggregation was made of professional stakeholders' responses. The useable response rate to the pre-implementation questionnaire was $74 \%(110 / 149)$ and this reduced to $68 \%$ post-implementation (88/129). Alpha coefficients of 0.79 and 0.87 respectively suggest that this questionnaire has a satisfactory level of internal consistency. Table 3 presents professional stakeholders' responses to a number of statements in the follow-up questionnaire. The table is based on responses from the FHNs' 78 professional colleagues.

These results show that professional colleagues were still unsure about the impact of many aspects of the FHN development, but also that the status quo had not been substantially altered so far. Few saw the FHN as taking away services and engendering deterioration. A comparison was also made using data from the 53 professional stakeholders who responded on both occasions and this showed very little overall shift in these stakeholders' perceptions.

At follow-up we also asked professional stakeholders whether they saw the need for a distinct FHN role locally. Thirty one percent responded affirmatively, $33 \%$ negatively, and $36 \%$ were unsure or gave no clear answer. Other professional nursing groups at the core of PHCTs tended to be less receptive to the new role than the wider spectrum of professional colleagues.

\section{Discussion}

\subsection{Implications for Scotland}

As a basis for discussion it is useful to map progress so far against the SEHD summary of the principles of the FHN role. The findings show that during the first year the FHNs usually functioned as skilled generalists encompassing a range of duties, but this engendered tension with in-depth family-as-client work. It is relevant to note that the nature of nursing engagement advocated in the North American concept of family nursing by authors such as Wright and Leahey (1994) and Friedman (1998) indicates a level of specialism in practice (Gillis 1999).

There was usually little change in terms of the FHNs being first point of contact (i.e. some FHNs were necessarily the first point of contact as there was no other type of nursing service immediately available; others would potentially be the first point of contact for their "inherited" district nursing caseload patients and a small number of other families). There was 
evidence that typically the FHNs were active in making referrals where more particular expertise was required.

Our study of practice showed that all the FHNs actively tried to take forward some work encouraging healthy living and preventing ill-health. For most, however, the main part of their job remained caring for ill members of the community requiring nursing care. This made it difficult for them to really develop a lead role in preventing illness and promoting community health at their home sites.

Consideration of the four principles for the Scottish FHN role highlights some of the differences that emerged through the typology, leading to the question: what factors make an FHN role work? From our findings so far it seems that there are two basic factors: the perceived scope and space to encourage implementing this approach; and the local presence of at least one active supporter who changes their own practice. The presence of at least one of these factors appeared to be a necessary condition for progress. Where neither of the foregoing conditions existed, family health nursing failed to thrive. During the evaluation we were also aware that the individual creativity and drive of the FHN were influential factors.

Whether these factors together are sufficient to further develop and sustain the role is doubtful. In our judgement the following factors were largely absent during the first year of family health nursing practice and are worth developing in order to sustain and promote the role of existing FHNs:

- a programme of support and facilitation of the development at site level.

- active team review of case loads and working practices to improve effectiveness and efficiency.

- concurrent review of nursing resources and staff skill mix.

- delegation of family health nursing work (possibly by putting FHN in a form of "triage" role, or as an active team leader).

In order to enable the role to merge with current service provision in a meaningful way, more Formatted: Bullets and work is also needed with core PHCTs so that focus on family and health is integrated and Numbering systematic. This would ideally be underpinned by concurrent efforts to engage patients and the wider community so that they expect, accept and value such an approach. 
In effect we found that the role could be developed in a limited way on top of a district nursing caseload and within pre-existing resources. Its introduction in these circumstances officially legitimised and raised awareness of nursing that has a strong family and health orientation in general. However many colleagues felt that this orientation already existed and consequently found it difficult to engage with, and understand the need for, this particular new approach. As such it has struggled to become a role in the sociological sense. Even where it was legitimised through recognition of its value (e.g. through referral of families) it could not necessarily be prioritised if traditional primary care provision was to be maintained unaltered.

The application of family health nursing to other remote and rural areas of Scotland or to the wider Scottish context requires careful consideration. A multi-skilled generalist nurse who can provide a range of services should be suited to remote and rural areas of Scotland where small teams exist and recruitment problems prevail. Whether the optimum knowledge and skill-base for this individual is premised on family health nursing requires careful assessment by service providers.

\subsection{Relevance to community nursing in the UK}

In effect this initiative has served to open up a spectrum of possibilities. The Bold build pattern represents one end of the practice spectrum. This casts the FHN as a further specialist community nurse whose work involves more in-depth programmes of care for families than those typically offered by district nurses and health visitors. Therefore if this role were to be developed in other villages or cities, with no concurrent revision of existing roles, this would be an extra service with cost implications.

At the other end of the spectrum the FHN is virtually synonymous with the District Nurse. In this context our research has shown that sustained development of family health care programmes is difficult if all other existing services are to remain unchanged. This was the case even where teams and caseloads were relatively small and stable. This would suggest more difficulty if the role were simply to be super-imposed on busy urban caseloads where throughput of individual patients may be much higher. Relevant UK research (Audit Commission 1999) strongly suggests that demand for an illness focused, medically responsive district nursing service remains a very high service priority.

What emerges strongly across the practice spectrum that we studied is the need for any introduction and development of the FHN role to be considered as part of wider service 
review and redesign. Thus we suggest that prior to introducing such a role service providers conduct comprehensive analysis to plan, facilitate and sustain the development. This should comprise situational analysis (e.g. what needs require to be met and what role(s) would best meet them?); role analysis (e.g. what work will be done in the new role?); cultural analysis (e.g. how will the new role fit with current understandings and PHCT practice); and business analysis (e.g. what resources are available to develop and sustain the role?). Such considerations would have relevance to urban applications and enhance the potential of the FHN role to be a solution to the particular problems of recruitment, development and retention of staff in remote and rural areas.

In many ways our considerations of the possible introduction of the FHN role are permeated by the idea of service design, and redesign, starting from the basis of local need. Nevertheless it is easy to see how more local interpretations could lead to further expansion of the FHN typology and consequent diversity, rather than necessarily creating one distinct, defined role. This reflects a tension between local needs and the need for national and international health services to share common understandings of nursing roles.

This tension has been palpable within UK nursing within the past two decades. Moves towards more specialist and advanced practice have engendered a profusion of new job titles (Tolson and West 1999; Cameron 2000). Community nursing has reflected this trend and often local necessity has driven evolution with professional education lagging somewhat behind (Spencer 2001). The UK educational framework for community specialist practitioners (UKCC 1994) was an attempt to address this but it can be argued that it has had the effect of reifying a fragmented and anomalous specialist superstructure for community nursing practice in the UK. For concurrently much of the nursing care delivered in communities has been devolved to registered nurses, nursing assistants and, arguably, home carers.

Therefore it is not surprising that, for some, resolution is seen in the form of a much more generic community nursing role. The WHO Europe FHN role represents one particular form of this through its focus on the family. The Scottish experience is significant in that, to our knowledge, it represents the first UK attempt to systematically introduce at national level a new higher-level generalist role into a field that is now characterised by differentiated specialist roles. It is important to note that the introduction of the role was being underpinned by an educational course that had to also satisfy the requirements of the pre-existing specialist practice framework. 
Underlying this difficult juxtaposition is the question of whether the FHN role should supplement or replace pre-existing community nursing roles in the UK. During our research some professionals raised the possibility of family health nursing replacing district nursing. Moreover this is implicitly suggested within recent Scottish policy (SEHD 2001). Our research suggests that simply replacing district nursing with family health nursing is likely to produce relatively minor change if the new incumbents are expected to maintain existing service priorities and work with whole families only when they have time.

Recent English primary care nursing policy (Department of Health 2002) values generalists in terms of support workers/health care assistants and registered nurses, but makes no mention of FHNs. Although some examples of innovation in family-focused care are cited in this document there is no particular policy emphasis or priority ascribed to the care of whole families.

Consideration of English policy is relevant as it raises the question: even if a new, higher level generalist community nursing role was deemed desirable, would it be useful to put such an overt emphasis on family? During the first year of the Scottish initiative the FHNs tried very hard to address whole families' needs through a detailed assessment and intervention framework that derived directly from the Calgary model. By the end of the year new abbreviated documentation had been produced which made the influence of this model much less overt. This reflected a pressure to spend less time on assessment and to adapt the more family specialist aspects of the role to the general demands of primary care practice.

\subsection{The broader European perspective}

It is interesting to note that the WHO Europe FHN curriculum is much less overtly influenced by North American thinking on family nursing than the Scottish initiative has been so far. The definition of family health nursing as set out by WHO Europe is broad in its aspirations to meet the needs of individuals, families and communities. Three concepts that have positive connotations but are notoriously difficult to define (viz. family; health; and nursing), have been combined within one role descriptor. What emerges from reviewing the limited, predominantly aspirational, literature that exists in relation to family health nursing so far is the need for caution in assuming that these commonly used terms have a unified meaning. Diverse practice examples pertinent to specific cultural groups are used by WHO Europe (2000) to exemplify the concept and articulate the ideology that a family health nursing approach to the delivery of care by nurses has universal utility. Such diversity helps to promote the ideology but makes for difficulty in articulating a unitary operational definition. 
Our empirical research into implementation found that the breadth of the role and its hypothetical nature made understanding and positive engagement difficult for many established Scottish health care professionals.

In effect the WHO Europe idea of family health nursing signifies an aspiration for a panEuropean nursing role. Within the main WHO Europe document (2000) family health nursing is portrayed as the central stanchion in the "umbrella of public health and primary health care". In a context where there is inadequate or no multi-disciplinary community health care provision then the WHO Europe Family Health Nurse-led service has the potential to be enacted with the nurse being the key co-ordinator of all services and referrals. However an umbrella has seldom been the covering of choice in remote and rural Scotland, and as a conceptual framework, and as a metaphor, this portrayal is rather naïve for a context where community health care provision is long established through resource deployment, professional power dynamics and political climate. Indeed during our research it was noticeable how little the FHN initiative threatened established inter-professional hierarchies. Advocates of the FHN role such as Kesby $(2000$; 2002) see the FHN as a nurse leader on equal partnership status with the GP, but the latter interpretation has not been a prominent feature of the Scottish experience.

This highlights the tension that exists between the WHO Europe aspiration for a definable pan-European community nursing role and the needs of individual countries involved in developing the FHN role. Progress in the latter regard has been slower than initially envisaged, with some countries struggling to secure financial infrastructure and develop appropriate educational preparation (Fawcett-Henesy 2003). Moreover the nature and scope of existing and envisaged service provision varies widely amongst interested countries. While countries such as Moldova are in a process of transition towards developing national primary health care systems, other countries such as Finland have longer established systems. The Scottish experience so far has particular relevance for countries in the latter category, but many of the issues raised in trying to enact this concept have more general currency (e.g. the need for nursing role development to link to broader service development).

The distinctive focus on family health inherent in the WHO Europe role raises fundamental questions about the nature and scope of national primary health care service provision. Hartrick (1997) highlights the tension between primary care provision of a service that is primarily problem-focused and the aspiration to enhance family capacity through health promotion. The latter wish is almost limitless in scope and poses both profound and practical questions for service managers if the whole family-as-client concept is to be integral to PHCT 
service provision. In this regard it is important to note that within parallel medical literature (WHO 1998b) there is limited concern for the focus of health care to move away from the individual client to that of the family as client.

\section{Conclusion}

The development of education, national policy and service delivery simultaneously is a very considerable challenge. Within Scotland, the extent of the challenge involved in introducing family health nursing has initially been underestimated. However the Scottish Executive has recently signalled its intention to act on the evaluation's findings by appointing local facilitators for existing FHN sites and developing the educational course (SEHD 2003). Moreover a pilot of the FHN role in an inner-city area will be developed. This initiative should illuminate whether the family health nurse concept can be meaningfully operationalised within a context where district nursing caseloads are typically heavy, have high throughput, and have high proportions of elderly people who live alone. Our initial evaluation suggests that this is unlikely unless the FHN role is more explicitly de-coupled from the provision of pre-existing district nursing services.

It seems likely that in the short term in Scotland there will be inherent ongoing tension between the distinctive family focus of the role and the demand within the system for generalist activities prioritised around individuals' needs. Whether this tension proves dysfunctional or not will depend on the extent to which the role can be facilitated, and the extent to which PHCTs recognise a need for this type of family health approach and are willing to prioritise service redesign activities accordingly. If the latter activities are successful it is possible to envisage the role developing significantly as part of more integrated, family orientated services. In turn this would lead towards a critical mass being achieved that would present a stronger argument to inform debate about changing the present UK system of community specialist nursing roles.

At the wider European level there is a need for more published information from the WHO Europe on the progress of role enactment. It is hoped that this first systematic study of the enactment of the WHO (Europe) FHN concept in practice will generate and inform much wider debate on the Family Health Nurse concept within Europe and beyond.

\section{Word count $=6738$}




\section{Acknowledgements}

The authors are grateful to all those who contributed to making the study possible, particularly the Family Health Nurses, their clients and professional colleagues. The study was funded by the Scottish Executive Health Department. However the views expressed in this article are those of the researchers and do not necessarily represent those of the Scottish Executive Health Department. 


\section{References}

Audit Commission, 1999. First Assessment: a review of District Nursing services in England and Wales. Audit Commission, London.

Bryman, A., 2001. Social research methods. Oxford University Press, Oxford.

Cameron, A., 2000. New role developments in context. In: Humphris, D., Masterson, A. (Eds.), Developing new clinical roles. Churchill Livingstone, Edinburgh.

Department of Health., 2002. Liberating the talents: helping Primary Care Trusts and nurses to deliver the NHS plan. Department of Health, London.

Fawcett-Henesy, A., 2003. Family Health Nursing: the international dimension. Conference presentation at the Family Health Nurse in Scotland Conference, Heriot Watt University, Edinburgh 31/10/03.

Friedman, M., 1998. Family Nursing Research, Theory and Practice. Appleton Lange, Conneticut.

Gillis, C., 1999. Family Nursing Research, Theory and Practice. In: Wegner, G., Alexander, R. (Eds.), Readings in Family Health Nursing. Lippincott, Philadelphia.

Goodman, C., Ross, F., Mackenzie, A., Vernon, S., 2003. A portrait of district nursing: its contribution to primary health care. Journal of Interprofessional Care 17 (1), 97-108.

Griffiths, J., Luker, K., 1994. Intraprofessional team work: in whose interest? Journal of Advanced Nursing 20 (6), 1038-1045.

Guba, Y., Lincoln, E., 1989. Fourth generation evaluation. Sage, London.

Hartrick, G., 1997. Beyond a service model of care. Journal of Family Nursing 3 (1), 57-69.

Hyde, V., 1995. Community nursing; a unified discipline? In: Cain, P., Hyde, V., Howkins, E., (Eds.) Community Nursing: dimensions and dilemmas. Arnold, London. 
Kesby, S., 2000. The return of the crossroads of opportunity: the conceptual evolution of the Family Health Nurse. Policy, Politics and Nursing Practice 1 (2), 116-123.

Kesby, S., 2002. Nursing care and collaborative practice. Journal of Clinical Nursing 11 (3), 357-366.

Macduff, C., West, B., 2003. Evaluating Family Health Nursing through education and practice. Scottish Executive Social Research, The Stationery Office, Edinburgh.

Osgood, C., Suci, C., Tannenbaum, P., 1957. The measurement of meaning. University of Illinois Press, Illinois.

Pawson, R., Tilley, N., 1997. Realistic Evaluation. Sage, London.

Priest, H., Roberts, P., and Woods, L., 2002. An overview of three different approaches to the interpretation of qualitative data. Part 1: theoretical issues. Nurse Researcher 10 (1), 30-42.

Scottish Executive Health Department, 2000. Scotland's people: results from the 1999 Scottish Household Survey: Volume 1. Scottish Executive, The Stationery Office, Edinburgh.

Scottish Executive Health Department, 2001. Nursing for Health. Scottish Executive, The Stationery Office, Edinburgh.

Scottish Executive Health Department, 2003. Family Health Nursing in Scotland: a report on the WHO Europe pilot. Scottish Executive, The Stationery Office, Edinburgh.

Spencer, S., 2001. Education for change. In: Spencer, S., Unsworth, J., Burke, W., (Eds.) Developing Community Nursing Practice. Open University Press, Buckingham.

Tolson, D., West B., 1999. An exploration of role development in Nursing and Midwifery: Scotland. Scottish Executive, The Stationery Office, Edinburgh.

United Kingdom Central Council for Nursing, Midwifery and Health Visiting, 1994. The future of professional practice - the Council's standards for education and practice following registration: programmes of education leading to the qualification of specialist practitioner. UKCC, London. 
World Health Organisation, 1998a. HEALTH 21: the health for all policy framework for the WHO European Region. WHO Regional Office for Europe (European Health for All Series No. 5), Copenhagen.

World Health Organisation, 1998b. The WHO framework for development of general practice/family medicine in Europe (EUR/ICP/DLVR040101). WHO Regional Office for Europe, Copenhagen.

World Health Organisation, 2000. The Family Health Nurse: context, conceptual framework and curriculum (EUR/OO/5019309/1300074). WHO Regional Office for Europe, Copenhagen.

Wright, L., Leahey, M., 1994. Nurses and families: a guide to assessment and intervention. Davis \& co, Philadelphia.

Yin, R., 1994. Case study research: design and methods. Sage, California. 


\section{Table 1: Typology of family health nursing practice}

\begin{tabular}{|c|c|c|c|}
\hline $\begin{array}{l}\text { Type } \\
\text { name }\end{array}$ & Characteristic context/process/outcome pattern (CPO) & $\begin{array}{l}\text { Evaluators' } \\
\text { judgement }\end{array}$ & Site codes \\
\hline $\begin{array}{l}\text { High } \\
\text { scope- } \\
\text { slow } \\
\text { build }\end{array}$ & $\begin{array}{l}\text { Context } \\
\begin{array}{l}\text { Small, stable caseload. High pre-existing scope for nursing autonomy and practice development } \\
\text { Process }\end{array} \\
\text { Gradual introduction by FHN only, with little/no change in other professionals working practices } \\
\text { Outcome }\end{array}$ & $\begin{array}{l}\text { Partial FHN } \\
\text { role } \\
\text { development }\end{array}$ & A, B \\
\hline $\begin{array}{l}\text { Slow/ } \\
\text { No go }\end{array}$ & $\begin{array}{l}\text { Context } \\
\begin{array}{l}\text { FHN role super-imposed on "heavy" district nursing caseload within established and functional medium sized PHCT } \\
\text { Process }\end{array} \\
\text { Sporadic and limited introduction by FHN only, with little/no change in other professionals working practices } \\
\text { Outcome } \\
\begin{array}{l}\text { No substantive change in practice. "Normal" district nursing services maintained, but remains stressful for FHN and } \\
\text { colleagues }\end{array}\end{array}$ & $\begin{array}{l}\text { Very little/ } \\
\text { thwarted FHN } \\
\text { role } \\
\text { development }\end{array}$ & $\mathbf{F}, \mathbf{G}, \mathbf{H},\left(\mathbf{J}^{*}\right)$ \\
\hline $\begin{array}{l}\text { Bold } \\
\text { build }\end{array}$ & $\begin{array}{l}\text { Context } \\
\text { "Heavy" district nursing caseload within established and functional medium sized PHCT, but FHN role not super-imposed } \\
\text { Process }\end{array}$ & $\begin{array}{l}\text { Substantial } \\
\text { FHN role } \\
\text { development }\end{array}$ & I \\
\hline
\end{tabular}

*Site J presented a slight variation of the Slow/No go pattern in that the role was super-imposed on a local management role (lead nurse) at a time of managing change towards an integrated hospital/community team. The FHN role was never developed in this context as it was felt that other work needed priority. 
Table 2: Comparison of the perceptions of 34 lay stakeholders who responded to the questionnaire pre and post introduction of FHN $(*$ denotes wording used when questionnaire sent post FHN introduction). Figures in bold text indicate actual number of respondents in each category and figures in brackets are percentages. Where row totals are less than 34 this indicates that the remainder of the respondents did not answer that particular question.

\begin{tabular}{|c|c|c|c|c|c|}
\hline \multicolumn{2}{|c|}{$\begin{array}{l}\text { I think the FHN will deliver } \\
\text { (delivers*) a different type } \\
\text { of service to what is currently } \\
\text { available }\end{array}$} & \multicolumn{2}{|c|}{ Unsure } & \multicolumn{2}{|c|}{$\begin{array}{l}\text { I think the FHN will deliver } \\
\text { (delivers*) a similar type of } \\
\text { service to what is currently } \\
\text { available }\end{array}$} \\
\hline Pre & Post & Pre & Post & Pre & Post \\
\hline $7(21 \%)$ & $6(18 \%)$ & $14(41 \%)$ & $11(35 \%)$ & $\mathbf{1 0}(29 \%)$ & $10(29 \%)$ \\
\hline
\end{tabular}

\begin{tabular}{|c|c|c|c|c|c|}
\hline \multicolumn{2}{|c|}{$\begin{array}{l}\text { I think the FHN will take } \\
\text { away (has taken away*) } \\
\text { from existing local services }\end{array}$} & \multicolumn{2}{|c|}{ Unsure } & \multicolumn{2}{|c|}{$\begin{array}{l}\text { I think the FHN will add to } \\
\text { (has added on to*) existing } \\
\text { local services }\end{array}$} \\
\hline Pre & Post & Pre & Post & Pre & Post \\
\hline $3(9 \%)$ & \begin{tabular}{|l}
$3(9 \%)$ \\
\end{tabular} & $19(56 \%)$ & $\mathbf{1 5}(44 \%)$ & $11(32 \%)$ & $9(27 \%)$ \\
\hline
\end{tabular}

\begin{tabular}{|c|c|c|c|c|c|}
\hline \multicolumn{2}{|c|}{$\begin{array}{l}\text { I think the FHN development } \\
\text { is well suited to our local } \\
\text { context }\end{array}$} & \multicolumn{2}{|c|}{ Unsure } & \multicolumn{2}{|c|}{$\begin{array}{l}\text { I think the FHN development } \\
\text { is not well suited to our local } \\
\text { context }\end{array}$} \\
\hline Pre & Post & Pre & Post & Pre & Post \\
\hline $19(56 \%)$ & $15(44 \%)$ & $10(29 \%)$ & $9(27 \%)$ & \begin{tabular}{|l}
$3(9 \%)$ \\
\end{tabular} & $3(9 \%)$ \\
\hline
\end{tabular}

\begin{tabular}{|c|c|c|c|c|c|}
\hline \multicolumn{2}{|c|}{$\begin{array}{l}\text { I think the FHN development } \\
\text { will lead to an improvement } \\
\text { in local health service }\end{array}$} & \multicolumn{2}{|c|}{ Unsure } & \multicolumn{2}{|c|}{$\begin{array}{l}\text { I think the FHN development } \\
\text { will lead to a deterioration } \\
\text { in local health service }\end{array}$} \\
\hline Pre & Post & Pre & Post & Pre & Post \\
\hline $12(35 \%)$ & $12(35 \%)$ & $20(59 \%)$ & $15(44 \%)$ & $1(3 \%)$ & $1(3 \%)$ \\
\hline
\end{tabular}


Table 3: Professional stakeholders' responses to questions post introduction of FHN

Figures in bold text indicate actual number of respondents in each category and figures in brackets are percentages. Where row totals are less than 78 this indicates that the remainder of respondents did not answer that particular question.

\begin{tabular}{|c|c|c|}
\hline $\begin{array}{l}\text { I think the FHN delivers a } \\
\text { different type of service to } \\
\text { what is currently available }\end{array}$ & Unsure & $\begin{array}{l}\text { I think the FHN delivers a } \\
\text { similar type of service to } \\
\text { what is currently available }\end{array}$ \\
\hline $\mathbf{1 2}(15 \%)$ & $\mathbf{3 5}(45 \%)$ & $\mathbf{2 9}(37 \%)$ \\
\hline
\end{tabular}

\begin{tabular}{|c|c|l|}
\hline $\begin{array}{l}\text { I think the FHN has taken } \\
\text { away from pre-existing local } \\
\text { services }\end{array}$ & Unsure & $\begin{array}{l}\text { I think the FHN has added } \\
\text { on to pre- existing local } \\
\text { services }\end{array}$ \\
\hline $\mathbf{7}(9 \%)$ & $\mathbf{4 6}(59 \%)$ & $\mathbf{2 2}(28 \%)$ \\
\hline
\end{tabular}

\begin{tabular}{|l|l|l|}
\hline $\begin{array}{l}\text { I think the FHN development } \\
\text { has involved substantial } \\
\text { change in the way that } \\
\text { services are delivered to } \\
\text { patients }\end{array}$ & $\begin{array}{l}\text { I think the FHN development } \\
\text { has involved minimal } \\
\text { change in the way that } \\
\text { services are delivered to } \\
\text { patients }\end{array}$ \\
\hline \multicolumn{1}{|c|}{$\mathbf{6}(8 \%)$} & $\mathbf{3 4}(44 \%)$ & \multicolumn{1}{|c|}{$\mathbf{3 3}(42 \%)$} \\
\hline
\end{tabular}

\begin{tabular}{|c|c|l|}
\hline $\begin{array}{l}\text { I think the FHN development } \\
\text { has involved substantial } \\
\text { change in way professions } \\
\text { work together }\end{array}$ & Unsure & $\begin{array}{l}\text { I think the FHN development } \\
\text { has involved minimal } \\
\text { change in way professions } \\
\text { work together }\end{array}$ \\
\hline $\mathbf{1 0}(13 \%)$ & $\mathbf{3 1}(40 \%)$ & \multicolumn{3}{|c|}{$(42 \%)$} \\
\hline
\end{tabular}

\begin{tabular}{|c|c|c|}
\hline $\begin{array}{l}\text { I think the FHN development } \\
\text { is well suited to our local } \\
\text { context }\end{array}$ & Unsure & $\begin{array}{l}\text { I think the FHN development } \\
\text { is not well suited to our local } \\
\text { context }\end{array}$ \\
\hline $23(29 \%)$ & $31(40 \%)$ & $19(24 \%)$ \\
\hline
\end{tabular}

\begin{tabular}{|c|c|c|}
\hline $\begin{array}{l}\text { I think the FHN development } \\
\text { will lead to an improvement } \\
\text { in local health service }\end{array}$ & Unsure & $\begin{array}{l}\text { I think the FHN development } \\
\text { will lead to a deterioration } \\
\text { in local health service }\end{array}$ \\
\hline $\mathbf{2 6}(33 \%)$ & $\mathbf{4 1}(53 \%)$ & $\mathbf{5}(6 \%)$ \\
\hline
\end{tabular}

\begin{tabular}{|c|c|c|}
\hline $\begin{array}{l}\text { I think the FHN development } \\
\text { is succeeding locally }\end{array}$ & Unsure & $\begin{array}{l}\text { I think the FHN development } \\
\text { is not succeeding locally }\end{array}$ \\
\hline $\mathbf{1 6}(21 \%)$ & $\mathbf{3 7}(47 \%)$ & $\mathbf{1 7}(22 \%)$ \\
\hline
\end{tabular}




\section{Figure 1: Process of selecting "tracer" and case study families}

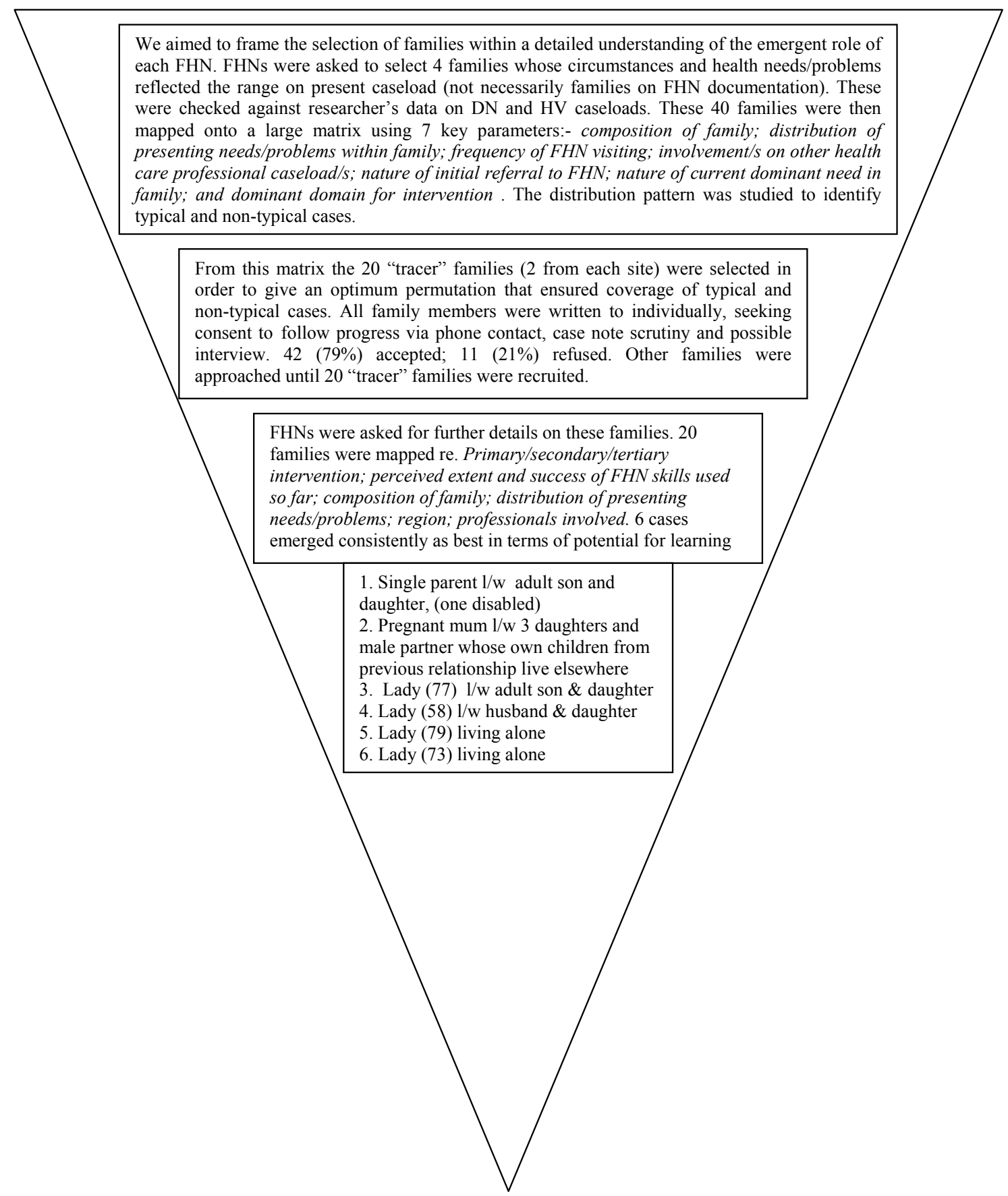




\section{Figure 2 : Process of analysis of data on FHN practice}

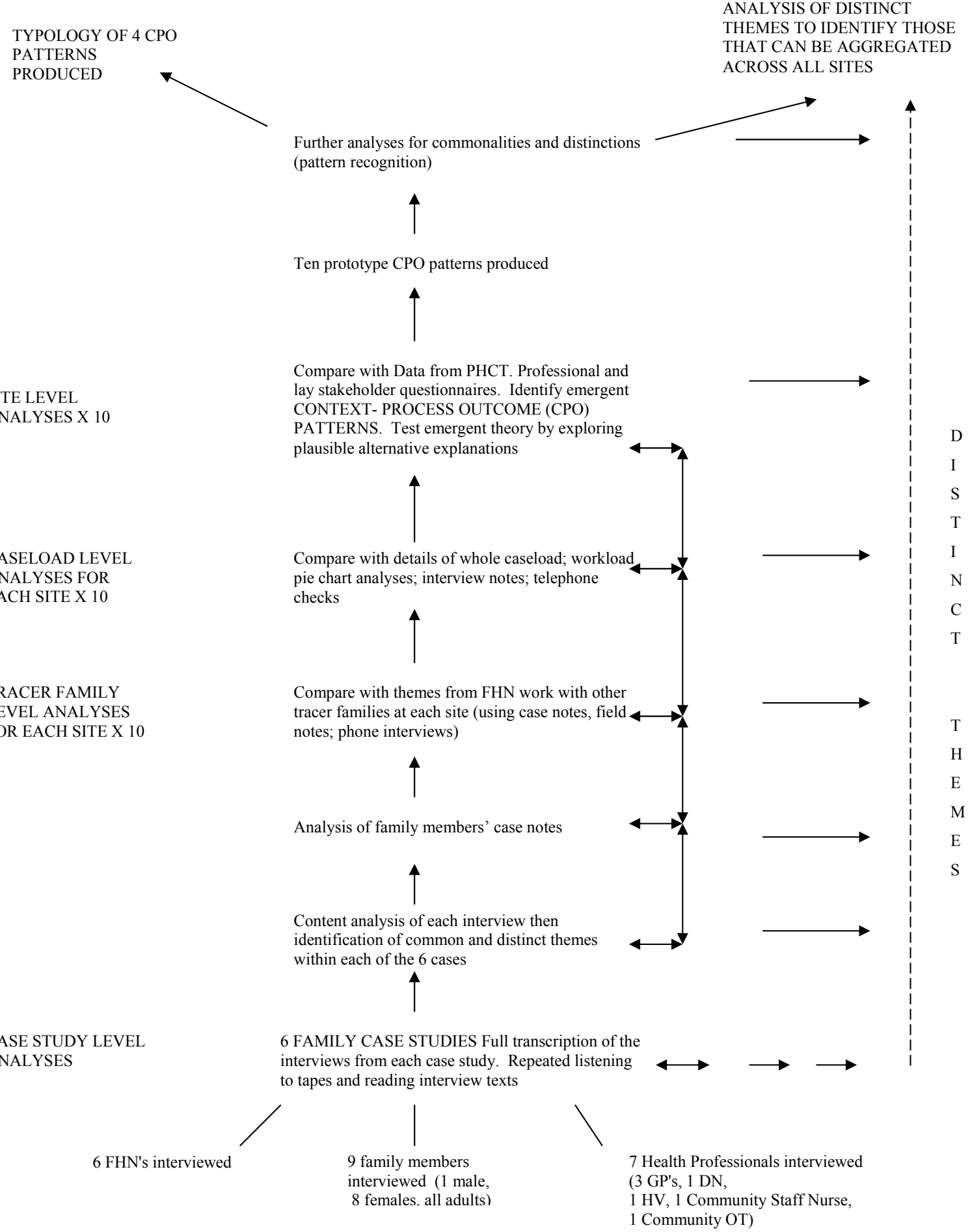

